\title{
Marjolin's Ulcer: Malignant Transformation From Burn Scar
}

\author{
Arif Tri Prasetyo a, Sitti Rizaliyana a, Iswinarno Doso Saputro a*

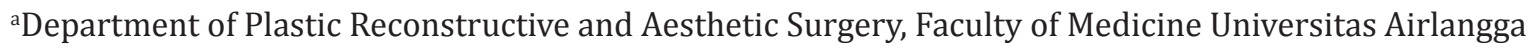

\section{ARTICLE INFO}

Keywords:

Marjolin's Ulcer

Burn

Scar

Reconstruction

\section{ABSTRACT}

Background: Marjolin's ulcer is malignant lesion from scar due to burn trauma, chronic osteomyelitis, chronic inflammation, or chronic fistulae. This type of ulcer is rare, usually progressively grow on unhealed wound, accompanied by chronic trauma especially burn scar. Marjolin's ulcer can form different types of pathologies'. Squamous cell carcinoma is the most type of histology. Previously, there was 3 Marjolin's ulcer reported in Indonesia.

Case Presentation: Reporting 3 Marjolin's ulcer case on Dr. Soetomo General Hospital since 2008 to 2016 . Two patients have history of unhealed chronic wound and one patient has history of burn injury 27 years ago. From the histopathology examination, all the results are squamous cell carcinoma. All patient undergo wide excision surgery done by surgical oncologist. All the defect is closed by flap modality. One patient's defect is closed by latissimus dorsi flap, the other with anterolateral thigh free flap, and the latter is closed by latissimus dorsi free flap. Remain raw surface close by split thickness skin graft.

Conclusion: Marjolin's ulcer is malignant lesion from scar due to burn trauma, chronic osteomyelitis, chronic inflammation, or chronic fistulae. Marjolin's ulcer sometimes grow become squamous cell carcinoma although require a long time. Treatment this case is same the other malignancy. Diagnosis should be confirmed by clinical, radiological, and pathological. Staging can use the classification of UICC (Union for International Cancer Control) in accordance with the histopathological results.
$\mathrm{M}$ alignant neoplasm arising in chronic, non-healing wounds has been known since ages and it was named Marjolin's ulcer about one hundred years ago. This scar malignancy arises in burned, constantly injured or chronically inflamed skin. Such pathologies as osteomyelitis, decubitus ulcers, chronic fistulas, frost bite, chronic venous failure, vaccination sites, skin graft donor sites and chronically traumatized skin are numbered among the etiological factors. ${ }^{1}$ The tumors behave aggressively and have a propensity for local recurrence and lymph node metastases. Marjolin's ulcer have a high tendency to metastasize. These lesions are, however, frequently overlooked and often inadequately treated. Early recognition and proper staging offers the best chance for cure. ${ }^{2}$

At all the burn will transform become Marjolin's ulcer, only 1-2\% of burn will develop into it. The malignant transformation last until 20 - 40 years after trauma. ${ }^{3}$ There are two variants of Marjolin's ulcer. In acute Marjolin's ulcer, the average latency is 4 months (range 4

\footnotetext{
* Coresponding author: Iswinarno Doso Saputro - Department of Plastic Reconstructive and Aesthetic Surgery, Faculty of Medicine Universitas Airlangga

Email address: iswinarno@yahoo.com (I. D. Saputro)
} 
weeks to 1 year), in the chronic type malignant changes are seen 1 year after arising, with an average latency period of 36 years. ${ }^{2}$ Studies have shown patients with Marjolin's ulcer have a decreased T-cell count, suggesting that immunosuppression is a contributory factor.' Whatever the exact mechanism, most researchers agree that a "cancerous environment" is formed because of the lack of blood supply and immunity in the scar tissue. The dry, thin, delicate epithelium covering the scar is easily destroyed by the trauma to which it is frequently subjected. ${ }^{4}$ The most common causes were chronic fistulae and burn scars. ${ }^{5}$

In most cases, histologically, Marjolin's ulcer is a squamos cell carcinoma (SCC) $73 \%$, followed by basal cell carcinoma (BCC) $10 \%$. Malignant melanoma, sarcomas (among them: fibrosarcoma, liposarcoma, dermatofi brosarcoma, protuberans, mesenchymal tumor), mixed tumors: SCC-BCC, SCC-melanoma are less frequent. ${ }^{1}$

Surgery is the main therapy of Marjolin's ulcer. This kind of malignancy has poor respond to radiotherapy. Multimodality of chemotherapy can be used to treat. But, there are no confirmed effective protocols for treatment of this disease. ${ }^{2}$

This paper will report our experience to treat 3 cases of Marjolin's ulcer. In Indonesia there are only 3 reported Marjolin's ulcer, one from Jakarta and the others from Yogyakarta. ${ }^{6}$

\section{CASE REPORT}

\section{Case 1}

Male 29 years old come to Plastic Reconstructive and Aesthetic Outpatient Clinic with chief complain painful lump on the head since 2 years before. Lump arising from the scar on the head. The size was small and become larger. There was smelly ulcer and pus on it. Patient felt discomfort with his condition and come to our clinic. He got history of burn when 2 years old due to hot cooking oil. He said that the burn already treated and heal in 3 months. After the injury, no hair grow on his head. On the age 14 years old, he felt embarrassed, and used wig to cover the baldness. He already use wig for more than 15 years.

From the physical examination, the general examination was found between normal limit. Inspection of his head region revealed tumor with size $16 \times 21 \times 4 \mathrm{~cm}$. There was an ulcer, pus, slough, and blood. The mass was solid, hard, brittle, easily bleed, fixed on the base, and painful. There was hypertrophic scar on the neck.

The scrapping examination shows squamous cell carcinoma. From radiologic examination, CT scan showed heterogenous enhancing solid mass on left temporoparietooccipitalis, brain parenchyma within normal limit. Patient diagnosed with Marjolin's ulcer squamous cell carcinoma T4N0M0.

Patient underwent wide excision surgery by surgical oncologist. During the surgery, the tumor shown to be infiltrating the calvaria with dimension $6 \times 4 \mathrm{~cm}$. The defect on calvaria was closed by neurosurgeon with acrylic and miniplate. From the vries coupe showed that the tumor was malignancy cell, squamous cell carcinoma, distance of the tumor to the nearest edge was $10 \mathrm{~mm}$.
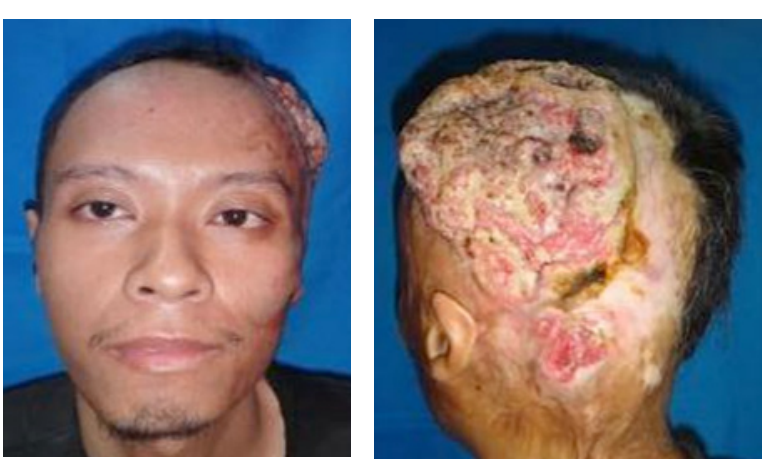

Figure 1. Clinical appearance at the first visit on outpatient clinic.

We close the defect with latissimus dorsi musculocutaneous free flap. We anastomose thoracodorsalis artery and vein with temporalis superficialis artery and vein. 2 months evaluation after surgery, the result was satisfied, the patient fell great with the result because he never smell the odor again. 


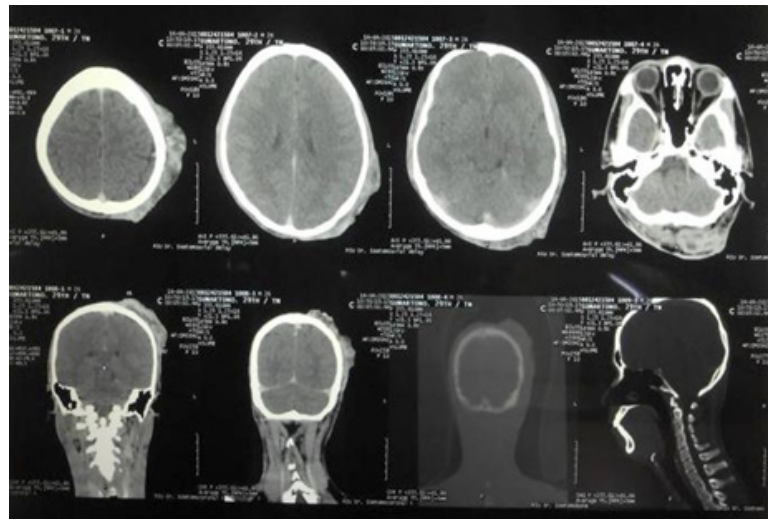

Figure 2. Head CT Scan examination showed no infitration to brain.
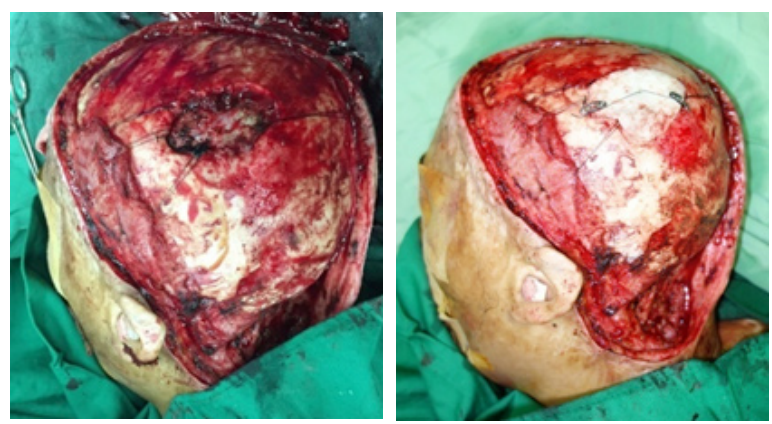

Figure 3. During the surgery there was infiltration to the calvaria, the defect was closed by neurosurgeon by acrylic and miniplate.
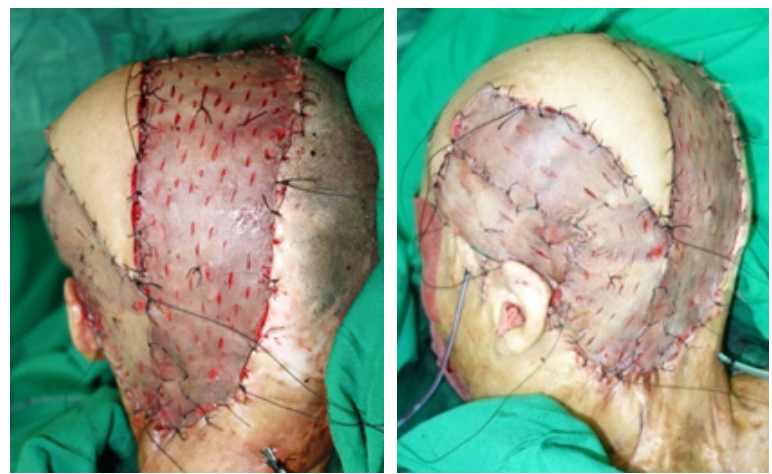

Figure 4. Immediate post-operative result. Defect was closed with latissimus dorsi free flap, remain raw surface was closed with split thickness skin graft.
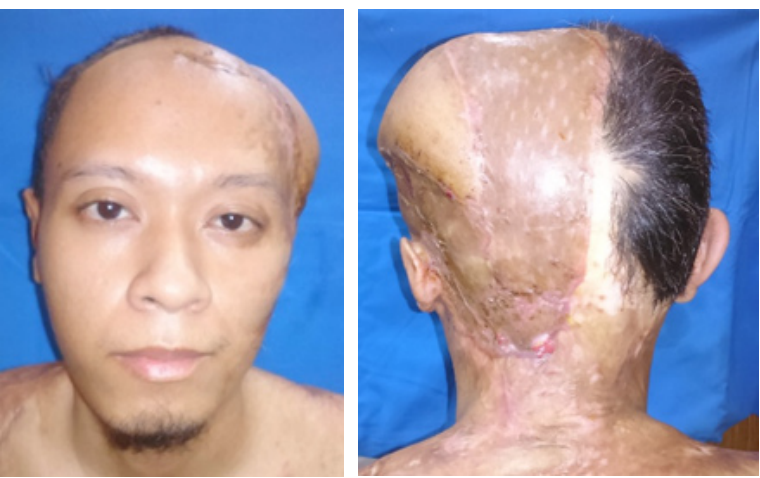

Figure 5. One month follow up after surgery. Patient fell satisfied with the result.

\section{Case 2}

Male 50 years old was consulted by Oncology Surgery division with chief complain mass on behind his left ear since a year before admission. He got history of burn at his head 10 years ago. It already healed and left scar. The mass was small and become bigger within 6 months. After that, ulcer occurs on the mass. Not only ulcer, but the mass also painful and smelly.

On physical examination, general examination was found within normal limit. Inspection of his retroauricula region revealed tumor with $18 \times 15 \times 5 \mathrm{~cm}$ in dimension. There was an ulcer, pus, slough, and blood. The mass was solid, hard, brittle, easily bleed, fixed on the base, and painful. There was hypertrophic scar on the neck.
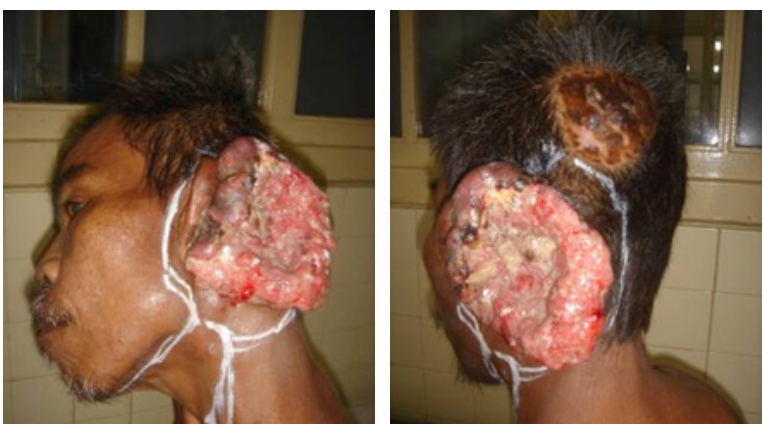

Figure 6. Clinical appearance at the first admission and incision design by surgical oncologist. 
Patient underwent wide excision surgery by surgical oncologist. The defect was closed with latissimus dorsi flap. Remain raw surface was closed with split thickness skin graft and the donor site was closed primarily. Evaluation on the ward, flap was viable but some split thickness skin graft didn't take. Patient underwent several surgical revision to close the defect with split thickness skin graft.

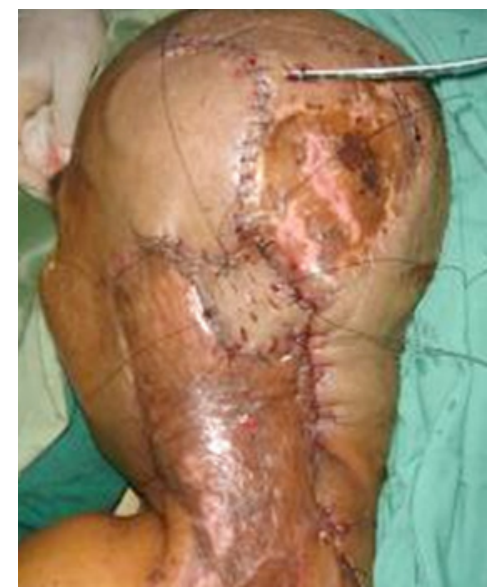

Figure 7. Immediate post-operative after the last surgery to closed the defect with split thickness skin graft.

\section{Case 3}

Male 66 years old was consulted by Oncology Surgery division with squamous cell carcinoma on ankle region. Patient got history of chronic wound on his ankle since 5 years ago and didn't heal properly until the wound become a mass and larger since 6 month before admission.

From general examination was found within normal limit. Inspection of his ankle region revealed tumor with $10 \times 8 \times 5 \mathrm{~cm}$ in dimension. It was a solid, odor, hard, brittle, easily bleed, fixed on the base, and painful mass. From the pathology examination, we discover a squamous cell carcinoma. CT-scan left ankle, there was no destruction on bone.

Patient was planned wide excision surgery by surgical oncologist and plastic surgeon closed the defect with anterolateral thigh free flap. The lateral circumflex femoral artery and vein was anastomosed with posterior tibialis artery and vein. The donor site was closed with split thickness skin graft.

\section{DISCUSSION}

Marjolin's ulcer is a rare and aggressive cutaneous malignant transformation with an incidence of $0.1 \%$ to $2.5 \%$ after a long-term inflammatory or traumatic insult to the skin. All the patient on this report came with mass and ulcer as a chief complain. The first patient had history of burn when his age was 2 years old. The mass arise after 27 years later on the scar. It is suitable with theory that this kind of malignancy can occur after 20 - 40 years after trauma. $^{3}$

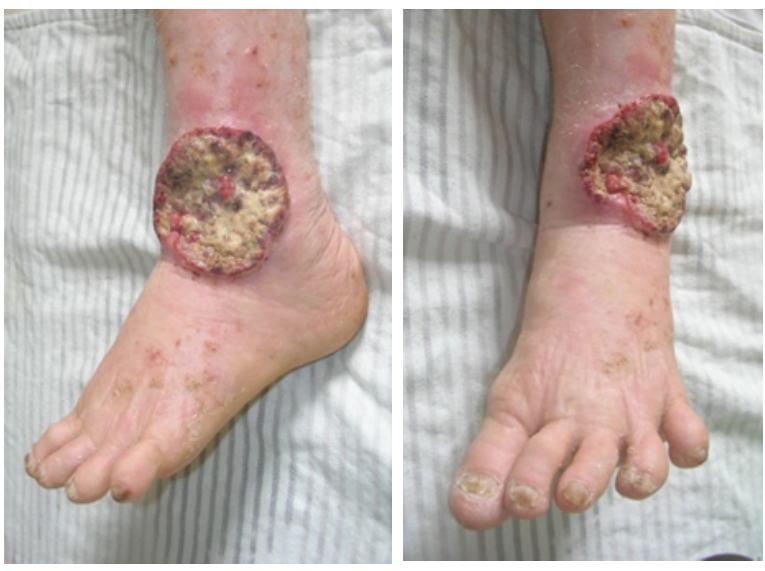

Figure 8. Clinical appearance at the first admission.

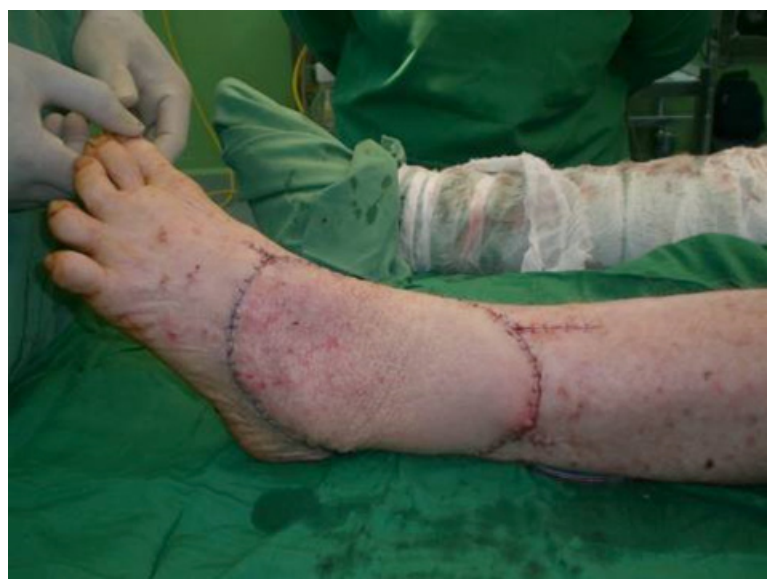

Figure 9. Immediate post-operative, defect was closed with anterolateral thigh free flap. 
The pathogenesis of Marjolin's ulcer has not been clearly established until now. Chronic skin trauma and scar tissue growth especially from burn injury, leads to an avascular condition which decreases the surveillance system of immunity cells against neoplastic cells, and this is suspected to be the cause. ${ }^{7}$

Numerous causative agents in the development of Marjolin's ulcers have been reported. These include Burn and non-burn traumas, osteomyelitis sinuses, pressure sores, urinary fistulas, pilonidal sinuses, gumata, radiation scars, and scars from 4 flogging, etc . The process of evolution of this scarred or chronically irritated skin into a malignant tumor is not clearly understood. Several theories have been propounded, but none fully explains all aspects of this evolution. Studies have also shown patients with Marjolin's ulcers have a decreased T-cell count, suggesting that immunosuppression is a contributory factor. ${ }^{8}$

Squamous cell carcinoma can be clinically classified using the tumor-nodemetastases (TNM) system. ${ }^{2}$ The SCC lesions in this patient clinically met the criteria of T4NOMO where T4 means the tumor has invaded extradermal structure based on MRI examinations. Physical examinations did not reveal regional lymph node metastases (N0), while chest $\mathrm{x}$ - ray and ultrasound found no distant metastases (M0). ${ }^{6}$

Based on TNM staging, all the patients were at stage III. Every patient underwent wide excision surgery with $2 \mathrm{~cm}$ safety margin. Post-surgical defect were covered with flap modality whether free flap or distant flap. The remained raw surface was covered with split thickness skin graft. The variability of the flap is operator preferred.

All the pathology results were squamous cell carcinoma. In most cases, histologically, Marjolin's ulcer is a squamous cell carcinoma (SCC) $-73 \%$, followed by basal cell carcinoma (BCC) - 10\%. Malignant melanoma, sarcomas (among them: fibrosarcoma, liposarcoma, dermatofi brosarcoma, protuberans, mesenchymal tumor), mixed tumors: SCC-BCC, SCC-melanoma are less frequent. ${ }^{1}$
Moreover, since the majority of MUs occur in long duration unstable scars of ungrafted full-thickness burns, the joint regions, especially flexion creases, are more commonly involved due to predisposition to activityrelated repeated ulceration. Early surgical management could also achieve a possible prevention strategy. ${ }^{9}$ Unstable scars and scars arising from burn wounds allowed to heal slowly have been shown to run a higher risk of malignant change. Deep burn wounds should be primarily grafted where possible, and unstable scars excised and grafted. Poor scars with a high risk of instability such as thick, hypopigmented inelastic scars across joints or mobile areas should be excised and replaced with supple tissue. It is important that such scar excisions should be adequate in depth as it is thought that dermal induction does occur. ${ }^{8}$

\section{CONCLUSION}

Marjolin's ulcer is a rare but highly aggressive ulcerating SCC. The formation of an ulcer in the latency period plays an important role in the course of Marjolin's ulcer. Based on the different length of the pre- and post-ulceration periods during the latency period, skin breakdown on chronic scars and chronic unhealed ulcers are two main sources of Marjolin's ulcer. This potentially fatal complication may be preventable and treatable by surgical management of initial injuries and early diagnosis and treatment of unhealed ulcers. Patients should be followed-up for the rest of their life, as Marjolin's ulcer is more aggressive than initial skin carcinomas. Surgery is the primary treatment for local control and radiotherapy has an adjunctive role that has to be backed by careful oncological surveillance.

\section{REFERENCES}

1. Ochenduszkiewics U, Matkowski R, Szynglarewicz B, Kornafel J. Marjolin's ulcer: malignant neoplasma arising in scar. 2016; 11(3): 135-8.

2. Aydogdu E, Yildirim S, Akoz T. Is surgery an effective and adequate treatmenr in advanced Marjolin's ulcer? Burns. 2005; 31(4: 421-31). 
3. Bonenkamp J. Squamous cell carcinoma and basal cell carcinoma of the skin. In Poston G, Beauchamp R, Ruers T. Textbook of Surgical Oncology. London: Informa UK Ltd; 2007. p. 305 - 306.

4. Malheiro E, Pinto A, Choupina M, Barroso L, Reis L, Amarante J. Marjolin's ulcer of the scalp: A case report and literature review. Ann of Burn and fire disaster. 2001.

5. Hahn S, KIM D, Jeon C. Clinical Study of Marjolin's ulcer. Yonsei Medical Journal. 1990; 31(3).

6. Laidding S, Atmowirdjo P. Squamous Cell Carcinoma Arising From Marjolin's ulcer Due To Post Burn Scar:
A Case Report. Jurnal Plastik Rekonstruksi. 2012 Jan; $1(1)$.

7. Soto-Davalos B, Corter-Flores A, Bandera-Delgaldo A, Luna-Ortiz K, Padilla-Rosciano A. Malignant neoplasm in burn scar; Marjolin's ulcer Report of two cases and revie of the literature. Cir. 2008; 76(35).

8. Opara K, Otene I. Marjolin's ulcers: A Review. The Nigerian Health Journal. 2011; 11(4).

9. Yu N, Lujan-Hernandez J, Hassan KZ, Bai M, Wang Y, Wang X, etal.Marjolin's ulcer: a preventable malignancy arising from scar. World Journal of Surgical Oncology. 2013; 11(313). 